\title{
PART SECOND.
}

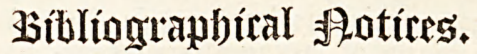

ART. I.-Dysphonia Clericorum, or Clergyman's Sore-Throat : its Pathology, Treatment, and Prevention. By James Mackness, M.D., Consulting Physician to the Hastings Dispensary.-London, 1848 . 8 vo, pp. 125.

THE affection which constitutes the topic of this treatise, is one which, though frequently trifling in itself, becomes of serious importance to the individual who suffers from it; curtailing his powers of usefulness, and, it may be, depriving him of his livelihood. There is no impropriety, then, in making it a special object of consideration; and it is well that the attention both of the profession and the public, should be formally called to it. We dislike all attempts, however, at popularizing strictly medical works; and think that Dr. Mackness would have done much better if he had addressed himself to one or the other class separately, rather than to both conjointly. The medical reader scarcely needs the introduction about Demosthenes and Cicero, Luther and Burke; nor does he require either the anatomical account of the air-passages and organs of speech which occupies the first chapter, or the exposition of the structure and properties of mucous membrane which fills the second. On the other hand, a large proportion of the subsequent details must be "caviare to the general." In our apprehension, Dr. Mackness would have done well. to have addressed to the speaking public his monitions on the causes and prevention of the disorder; and to have put forth his opinions on its pathology and treatment through the medical journals.

We believe that our author is, on the whole, correct in the view which he takes of the affection; namely, that it is in its simplest form a state of chronic irritation of the mucous membrane of the larynx and adjacent parts, frequently aggravated by a disordered state of the general health, and even passing on to ulceration; but that it is only in cases in which a tubercular diathesis previously exists, that this presents the characters of the disease described by Dr. Horace Green, of New York, under the title of "Tubercular Sore-Throat." He imputes the frequency of the ailment among clergymen, to the prevalent want of constitutional vigour and insufficient attention to the laws of health; and in this, also, we believe, that he is not far wrong. He lays great stress, therefore, on hygienic measures; and devotes to them a long chapter, which is, in fact, a brief "self-contained" treatise on the art of preserving health, such as would be quite superfluous in a purely medical work. In regard to local treatment, he speaks highly of the application of a strong solution of nitrate of silver to the diseased 
surface, in the manner recommended by Dr. Green. Full details on this point, however, having been very recently given by one of our predecessors, we need not here repeat them. (Brit. and For. Med. Review. Vol. XXIV, pp. 500-3.)

We think it well to notice one point in the etiology of this disorder, which seems to have been overlooked by Dr. Mackness, and which is of considerable importance. Dr. Mackness adverts to the continued strain upon the vocal organs which is kept up in the exercise of clerical or forensic duties, as a source of laryngeal irritation; but he leaves out of consideration the interruption to the ordinary respiratory process, which, we are convinced, has much to do with the general exhaustion and debility consequent upon such efforts in most of those who are frequently called upon to make them. Let any one observe the respiratory movements of a public speaker; and he will see that, instead of breathing from sixteen to eighteen times in a minute, his respirations are not above half, or even one third of that number; moreover the inspirations are short and hurried, whilst the expirations are retarded to such a degree as to occupy nearly the whole of the period that ought to be equally divided or nearly so. In carrying on a conversation, the continual interruptions give the needed relief by allowing the renewal of the ordinary respiratory movements; but in the delivery of a sermon, lecture, or speech, no such opportunities occur, and the sum total of the respiration during the period thus occupied must be far less than its normal standard. We need not tell our readers what must be the consequence of the habitual operation of such a cause; but we may direct their attention specially to the fact, as not improbably aiding in the development of the tubercular diathesis, which is favoured by anything that impedes the due aeration of the blood.

What means, then, can be suggested for the prevention of this evil? Obviously the performance of a natural respiratory movement as frequently as possible during the elocutionary effort. This, no doubt, may occasionally somewhat mar the rhetorical effect; yet we believe that the general fault of public speakers is too great rapidity, and that more frequent and longer pauses, during which the chest may be emptied and refilled, would be beneficial to their audience as well as to themselves. Thus one piece of advice given to young preachers by the late Rev. C. Simeon, of Cambridge, was to the following effect: "Let there be the same kind of pause and of emphasis, as a man has in conversation when he is speaking on some important subject." We have reason to believe that a secret for the prevention of the discomforts alluded to, which has been sold at the rate of twenty guineas to each individual to whom it has been revealed, and which has been found effectual enough to induce many clergymen to spend their money in purchasing it, is nothing more nor less than the rule we have just hinted at,-namely, to make pauses as frequently as possible, during which the chest should be first emptied and then refilled. The voice should always proceed from a full chest; for if vocalization be continued until the lungs are emptied or nearly so, it can only be by a most injurious retardation of the expiratory movement. It is a common error, when pause is made, to make a quick and sudden inspiration; this only serves to replace the air already expired, and the remaining carbonised atmosphere of the interior of the chest is still 
retained there. In order to get the full advantage of the pause, the expiration should be first completed; and the lungs then refilled with pure air. A little attention will soon enable this method to be practised without serious injury to the elocutionary effect, and with a most beneficial change in the feelings of the speaker.

Notwithstanding the comments we have thought it right to make on Dr. Mackness's treatise, we are bound to say that it contains a better account of the disorder in question, than has yet been laid before the British public; and that it may therefore be advantageously consulted by the medical practitioner as well as by the public speaker.

\section{Art. II.-Treatise on the Falsifications of Food, and the Chemical Means} employed to detect them. By JoHn Mitchelu, M.c.s., Author of 'Manual of Practical Assaying.'-London, 1848. Fcap. 8vo, pp. 334.

THE objects of this little treatise, as stated by its author, are "to point out a few of the adulterations practised by the manufacturers and vendors of various articles employed in domestic economy; as well as to show in what manner such adulterations can be readily and easily detected." Many of our readers, doubtless, remember the treatise on 'Culinary Poisons,' published some thirty years ago, by Mr. Accum, for the purpose of calling attention to the adulterations practised upon almost every article of food; and will recollect that either the same or some other work having similar objects, was advertised under the title of 'Death in the Pot.' Since that time the ingenuity of the fraudulent dealer has suggested many new adulterations, in which he has been aided by the advance of chemical knowledge; whilst a corresponding progress in the analytical department has led the chemist towards more ready and certain means of ascertaining the ordinary impurities in articles of food, as well as towards the detection of the newer and more carefully devised sophistications. A new treatise was therefore required; and Mr. Mitchell has supplied the deficiency in a very creditable manner. The following are enumerated by him as the purposes of these adulterations.

" 1 . To make the substance more saleable by improving its appearance, by the addition of some body either innocuous or otherwise.

" 2 . To depreciate its quality, by adding to it some substance which will diminish its real, without altering its apparent strength or general appearance. This is generally a very deadly fraud.

" 3 . To depreciate its quality by the addition of some simple substance, as water, or if it be a solid body, as plaster of Paris, sand, \&c." (p. viii.)

As an illustration of the first may be noticed the adulteration of bread with alum, carbonate of ammonia, carbonate of magnesia, the sulphates of copper and zinc, \&c.; all of which are employed to improve the appearance of the article, especially when it is made from inferior flour. From the statements of the author, it would appear that the London bakers' bread almost invariably contains alum, in quantities varying from $34 \frac{1}{2}$ grains to 116 grains in the $4 \mathrm{lb}$. loaf. As an example of the second, may be cited the adulteration of porter by cocculus indicus, quassia, \&c., 